\title{
Energy Saving Potential of the Organic Rankine Cycle in a Desiccant-assisted Ventilation System for a Residential Building
}

\author{
Hye-Won Dong ${ }^{1}$, Hansol Lim ${ }^{1}$, Hye-Jin Cho ${ }^{1}$, Yoo-Suk Byon ${ }^{1}$, Jae-Weon Jeong ${ }^{1, *}$ \\ ${ }^{1}$ Department of Architectural Engineering, Hanyang University, Seoul, Republic of Korea
}

\begin{abstract}
The purpose of this study is to evaluate the primary energy saving potential of an organic Rankine cycle integrated with a liquid desiccant and evaporative cooling-assisted ventilation system in a residential building. In cases where non vapor-compression-based systems are used, an evaporative cooler can lower the temperature of processed air using the latent heat of vaporization of water, while a liquid desiccant system can enhance the cooling effect of the evaporative cooler and dehumidify the processed air. This system can operate each component independently according to outdoor air conditions and can provide sensible cooling while meeting the ventilation requirements of the space considered. The organic Rankine cycle driven by a district heat source is applied to the ventilation system, and the heat and power generated are assumed to be used for the operation of the system. A simulation study was conducted during the cooling season that showed an adequate performance for the cooling system. The primary energy consumption of the proposed system was compared to the same ventilation system that was powered by a conventional grid power system and a boiler.
\end{abstract}

\section{Introduction}

Recent studies proposed the use of a liquid desiccant evaporative cooling-assisted, $100 \%$ outdoor air system, commonly referred to as LD-IDECOAS, and evaluated the its energy saving potential (Kim et al., 2013, 2014 , 2015). The LD-IDECOAS is a thermally driven cooling system that uses liquid desiccant (LD). When the LD system operates in the summer, it requires a relatively low-grade heat source to regenerate a weak desiccant solution. The regeneration energy accounts for the majority of energy consumption in the liquid desiccantassisted evaporative cooling system. Therefore, a renewable energy or combined heat and power system acts as an alternative heat source. Kim et al. (2016) revealed that the LD-IDECOAS integrated with a proton exchange membrane fuel cell saved $21 \%$ of the primary energy compared to that of the system that was powered by grid power and a boiler. Dong et al. (2017) evaluated the applicability of a district heat source that was applied to a desiccant-enhanced evaporative (DEVap) cooling system based on the comparison of its energy consumption with that of the same system that was served by a boiler. The findings indicated that the DEVap with the district heat source reduced the primary energy consumption by $46.2 \%$.

Consequently, the current study was conducted to evaluate the primary energy saving potential of an organic Rankine cycle (ORC) integrated with LD-IDECOAS in a multiple occupancy residential building. A district heat source was selected as the heat source of the ORC. The primary energy consumption of the LD-IDECOAS served by ORC was compared to an LD-IDECOAS served by a conventional grid power system and a boiler. Additionally, a simulation study was conducted during the cooling season that evaluated the performance of the cooling system.

\section{System overview \\ LD-IDECOAS}

The LD-IDECOAS was composed of a liquid desiccant (LD) system, an indirect evaporative cooler (IEC), and a direct evaporative cooler (DEC). A heating coil and a sensible heat exchanger were installed for the heating mode operation. The supply airflow rate was modulated based on the zone load as in a conventional variable air volume (VAV) system. In the cooling season, the hot and humid outdoor air (OA) was dehumidified by the LD unit and sensibly cooled by the IEC. Subsequently, the supplied air (SA) was cooled further by the DEC to satisfy the set temperature of the $\mathrm{SA}$ (i.e., $15^{\circ} \mathrm{C}$ ). In the heating season, the IEC operates as a sensible heat exchanger by recovering heat from the exhausted air (EA). The LD and DEC are deactivated during the heating season.

The LD system was integrated to enhance the cooling effects of the indirect and direct evaporative coolers. This system consisted of an absorber and a regenerator. A lithium chloride aqueous solution was used as a desiccant solution. Additionally, water-side free cooling with a cooling tower was introduced to reduce the cooling energy consumption of the absorber. Conversely, a heating device was required to maintain the regenerator's performance.

The IEC was composed of primary and secondary channels. During the cooling season, the SA that passed through the dry channels was cooled by transferring its sensible heat to the secondary air that underwent evaporative cooling in the secondary channel. The DEC isentropically cooled the SA to meet the set temperature of the SA. The air leaving the DEC was humidified 
instead of initially dehumidifying the SA in the LD system. building energy simulation software (i.e., TRNSYS 18). The operating energy consumption of the LD-IDECOAS was calculated by a commercial equation solver program

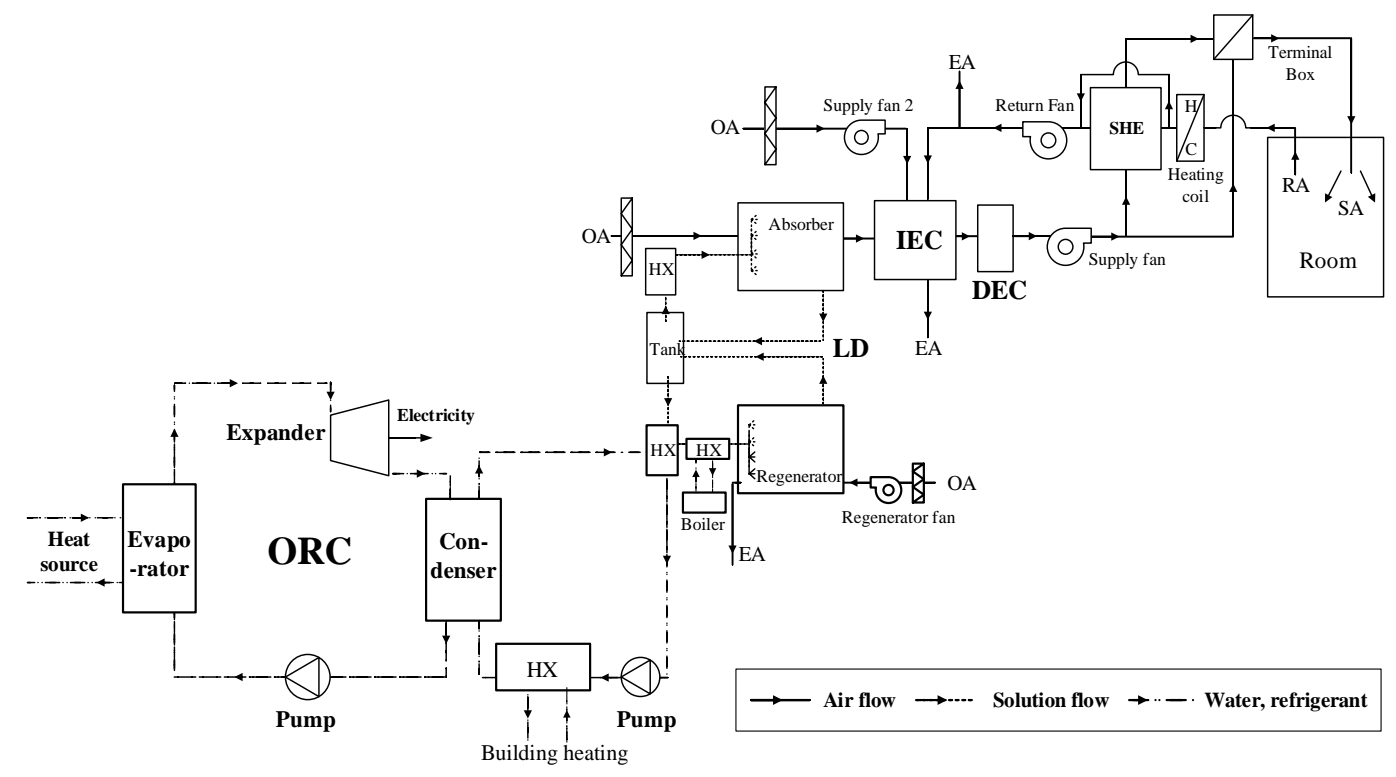

Figure 1: LD-IDECOAS

\section{LD-IDECOAS with organic Rankine cycle}

In this research study, a system that combines the LDIDECOAS with an ORC is proposed (Figure 1). The ORC typically consists of a turbine (or expander), an evaporator, a condenser, and a pump, and it requires a relatively lowtemperature heat source to generate electricity in the turbine and release heat in the condenser, thus operating as a CHP system.

The power of the ORC unit considered in this study was rated at $2 \mathrm{~kW}$ with NOVEC649 as the working fluid. Because the hourly demand of the proposed system did not exceed $2 \mathrm{~kW}$, a $2 \mathrm{~kW}$ ORC unit was used. The evaporating and condensing temperatures of the ORC used in this research were $105^{\circ} \mathrm{C}$ and $60^{\circ} \mathrm{C}$, respectively.

The electricity produced by the ORC operation initially met the power demand of the LD-IDECOAS package unit. The heat released from the ORC condenser is used for the regeneration of the desiccant solution. If the desiccant solution in the regenerator cannot be heated to the regenerating set point (i.e., $60{ }^{\circ} \mathrm{C}$ ) by the heat from the $\mathrm{ORC}$, an auxiliary heater is activated. The ORC-generated power and the heat that remain after the use for the LDIDECOAS operation are supplied to the building for the needs of its occupants.

\section{Energy Simulations}

First, the model building was introduced to calculate the building load. The estimated load was then used for the operating energy calculation of the air conditioning system. The residential building model is located in Seoul at the Republic of Korea. Table 1 shows the details of the model building, and Figure 2 shows its floor plan. Energy simulations were conducted during the cooling season (i.e., June, July, and August). The hourly cooling load profile of the model building was obtained by using the (i.e., EES) by using each of the component models.

Table 1: Building information

\begin{tabular}{|c|c|c|c|}
\hline Weather & \multicolumn{3}{|c|}{ Weather data for Seoul } \\
\hline \multirow{2}{*}{$\begin{array}{c}\text { Target } \\
\text { room } \\
\text { condition }\end{array}$} & Temperature & \multicolumn{2}{|c|}{$26^{\circ} \mathrm{C}$} \\
\hline & $\begin{array}{l}\text { Relative } \\
\text { humidity }\end{array}$ & \multicolumn{2}{|c|}{$50 \%$} \\
\hline \multirow{2}{*}{$\begin{array}{l}\text { Internal } \\
\text { heat gain }\end{array}$} & \multirow{2}{*}{ People } & Sensible & $\begin{array}{c}75 \\
\text { W/person }\end{array}$ \\
\hline & & Latent & $\begin{array}{c}75 \\
\text { W/person }\end{array}$ \\
\hline \multirow{4}{*}{$\begin{array}{c}U \text { values } \\
\text { (window- } \\
\text { to-wall } \\
\text { ratio: } \\
17 \% \text { ) }\end{array}$} & Floor & \multicolumn{2}{|c|}{$0.952 \mathrm{~W} / \mathrm{m}^{2} \cdot \mathrm{K}$} \\
\hline & Roof & \multicolumn{2}{|c|}{$0.630 \mathrm{~W} / \mathrm{m}^{2} \cdot \mathrm{K}$} \\
\hline & Exterior wall & \multicolumn{2}{|c|}{$0.468 \mathrm{~W} / \mathrm{m}^{2} \cdot \mathrm{K}$} \\
\hline & Window & \multicolumn{2}{|c|}{$5.68 \mathrm{~W} / \mathrm{m}^{2} \cdot \mathrm{K}$} \\
\hline
\end{tabular}

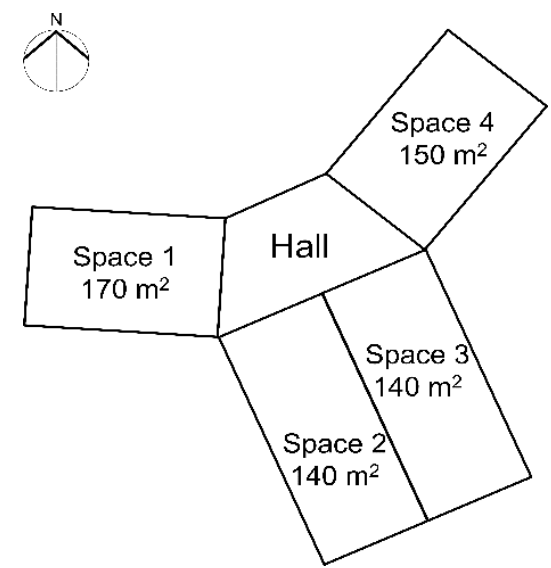

Figure 2: Floor plan of simulated building 


\section{Liquid desiccant}

The LD performance is represented by the effectiveness value of the moisture transfer process. The absorber effectiveness model proposed by Chung and Luo (1999) was used for the absorber. The liquid-to-gas ratio of the absorber was set to the value of two. In this study, the Martin and Goswami (2000) model was applied in the regenerator side. The liquid-to-gas ratio of the regenerator was set to a value of four.

The dimensions or inlet parameters of the LD system used in the simulation were based on the LD-IDECOAS pilot system (Kim et al., 2015). The specific surface areas of the absorber and regenerator were both equal to 223 $\mathrm{m}^{2} / \mathrm{m}^{3}$. The concentration of the inlet solution of the absorber was set to $40 \%$. The initial desiccant cooling and heating temperature were set to $30{ }^{\circ} \mathrm{C}$ and $60{ }^{\circ} \mathrm{C}$, respectively. It was assumed that the dehumidification and regeneration rates were equal.

\section{Evaporative coolers}

There are two evaporative coolers, namely the IEC and DEC. The leaving air conditions of each evaporative cooler were calculated in accordance with Equations 1 and 2. The effectiveness rates of the indirect and direct evaporative coolers were assumed to be $80 \%$ and $95 \%$ (Kim et al. 2014), respectively.

$$
\begin{gathered}
\varepsilon_{\mathrm{IEC}}=\frac{\mathrm{DBT}_{\mathrm{abs}, \text { out }}-\mathrm{DBT}_{\mathrm{IEC}, \text { out }}}{\mathrm{DBT}_{\mathrm{abs}, \text { out }}-\mathrm{WBT}_{\mathrm{IEC}, \text { s, in }}} \\
\varepsilon_{\mathrm{DEC}}=\frac{\mathrm{DBT}_{\mathrm{IEC}, \text { out }}-\mathrm{DBT}_{\mathrm{DEC}, \text { out }}}{\mathrm{DBT}_{\mathrm{IEC}, \text { out }}-\mathrm{WBT}_{\mathrm{IEC} \text {,out }}}
\end{gathered}
$$

\section{ORC}

The ORC is typically composed of a turbine, a compressor, a condenser, and a pump. The ORC is based on a conventional Rankine cycle. In this study, the simplified model that was developed by Quoilin (2011) was used. The NOVEC 649 was used as the working fluid. The ORC was operated at a full load (i.e., $2 \mathrm{~kW}$ power) based on the HVAC schedule. Water was used as the cooling fluid for the condenser and as a heating fluid for the evaporator. The efficiencies of the turbine and pump were assumed to be equal to $90 \%$. The evaporation and condensing temperatures were set to $105{ }^{\circ} \mathrm{C}$ and $60{ }^{\circ} \mathrm{C}$, respectively. The calculated ORC efficiency was $9.1 \%$. The power generated from the ORC can be supplied to the building for air-conditioning operation or lighting, and the heat recovered from the ORC is used as solution heating or building space heating.

It was assumed that the model residential building was served by a district heat source (DHS) and the ORC used DHS as a heat source of ORC. The temperature of the DHS source was assumed to be $120^{\circ} \mathrm{C}$, and the district heat was assumed to have a 5\% heat loss owing to distribution.

\section{Boiler and cooling tower}

To compare the energy consumption with the use of ORC with that of a conventional gas boiler, it was assumed that a hot-water boiler was located inside the building and was used for the heating of the regenerator solution. The theoretical efficiency of the boiler was set to $82 \%$ in this study (EnergyPlus, 2013). The cooling tower was operated for the cooling of solutions for both the ORC and the conventional LD-IDECOAS. The cooling approach and range were set to $2{ }^{\circ} \mathrm{C}$ and $10{ }^{\circ} \mathrm{C}$, respectively.

\section{Fans and pumps}

The LD-IDECOAS included three variable air volume fans, namely supply, return, cooling tower, and regenerator fans. The fan efficiency $\left(\eta_{\text {fan }}\right)$, airflow rate $\left(\dot{\mathrm{V}}_{\text {fan }}\right)$, and pressure loss $(\Delta \mathrm{P})$, are the required variables (Equation 5) for the fan power $\left(\mathrm{P}_{\mathrm{fan}}\right)$ calculation. The pressure loss of the fan from Kim et al. (2016) was based on a rate of $1000 \mathrm{~m}^{3} / \mathrm{h}$. Correspondingly, the actual pressure loss in this study (i.e., $2000 \mathrm{~m}^{3} / \mathrm{h}$ ) was calculated based on the fan affinity law for pressure loss.

Pumps are required for the absorber, regenerator, cooling tower, IEC, and DEC. When integrated with the ORC or solar thermal system, it is necessary to install the additional circulation pumps. The required variables for the calculation of the pump power $\left(\mathrm{P}_{\text {pump }}\right)$ include the pump efficiency $\left(\eta_{\text {pump }}\right)$, fluid density $(\rho)$, flow rate $\left(\dot{\mathrm{V}}_{\text {pump }}\right)$, gravity acceleration $(\mathrm{g})$, and head loss $(\mathrm{H})$ (Equation. 6). The assumed head loss of the pump was based on the findings of the publication by Kim et al. (2016). The expressions are as follows,

$$
\begin{gathered}
\mathrm{P}_{\text {fan }}=\left(\dot{\mathrm{V}}_{\text {fan }} \cdot \Delta \mathrm{P}\right) / \eta_{\text {fan }} \\
\mathrm{P}_{\text {pump }}=\rho \cdot \mathrm{g} \cdot \dot{\mathrm{V}}_{\text {pump }} \cdot \mathrm{H} / 1000 \cdot \eta_{\text {pump }}
\end{gathered}
$$

\section{Primary energy factor}

The power and heat consumption of each component were converted into primary energy consumption. It was assumed that the electricity was supplied from the existing power grid in both cases, and that LNG was used for the gas boiler. The regional condition was considered, and the primary energy factors were introduced for each energy source, as recommended by the Korean Energy Agency. The local primary energy factors corresponded to 2.75 for electricity, 1.1 for fuel, and 0.728 for district heat.

\section{Results}

The energy performance evaluation of the LD-IDECOAS driven by ORC was conducted during the cooling season (i.e., June, July, and August). Figure 3 shows a comparison of the energy consumption between the district heat source ORC LD-IDECOAS and the base LD-IDECOAS systems. The power consumption was the sum of the fan and pump energies. This consumption differed from that of the conventional variable air volume system in which the consumption of the chiller accounted for the highest proportion of the power consumption. This is because the LD-IDECOAS corresponds to a type of nonvapor compression system that provides both sensible and latent cooling without or with minimum use of the chiller. The electricity load for the LD-IDECOAS is the same in both cases. However, the district heat source of the combined ORC/LD-IDECOAS system required a load that was 1.20 times the load required by the base LDIDECOAS system owing to the ORC operation. 
The heating load was required for solution heating and air reheating. To operate the ORC system, a heat source was also needed in the evaporator. The ORC system that was integrated with the LD-IDECOAS minimized the solution heating load compared to that required in the case of the base. However, they required the ORC heat source. Finally, the ORC LD-IDECOAS required a heating load that was 1.07 times the heating load required by the base. Consequently, the proposed system saved $34 \%$ of the primary energy consumption by recovering the waste heat from the ORC condenser compared to the same air conditioning system served by the conventional grid power and boiler.

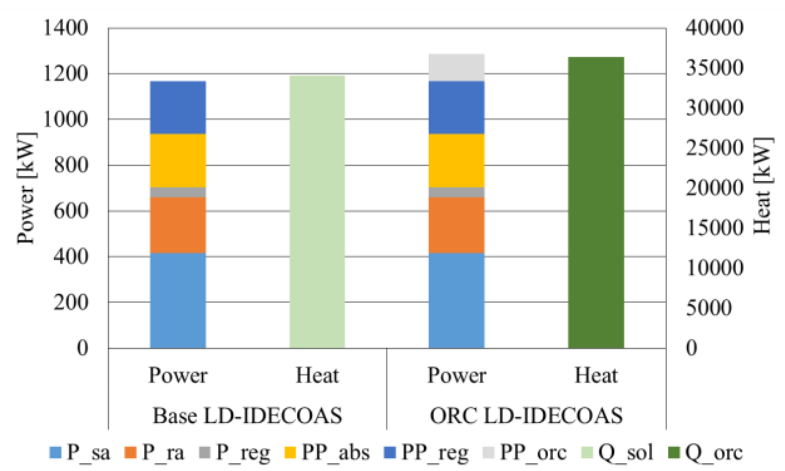

Figure 3: Comparison of energy consumptions

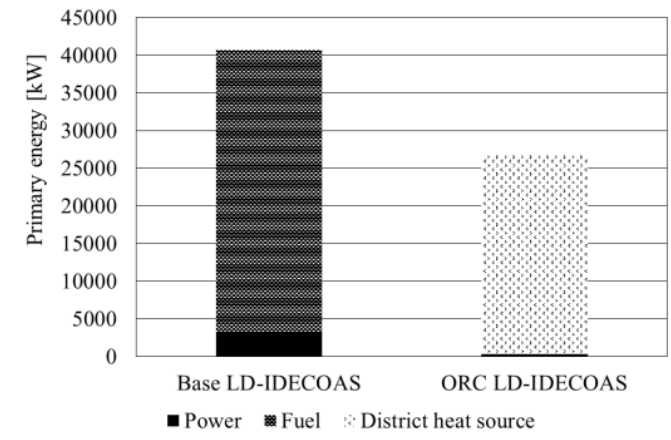

Figure 4: Comparison of primary energy

\section{Conclusions}

This study was conducted to a) evaluate the primary energy consumption of the ORC applied to the LDIDECOAS and $b$ ) to compare the combined system to the LD-IDECOAS served by a conventional grid power and a boiler during the cooling season. The results indicated that the DHS-ORC LD-IDECOAS saved $34 \%$ of the primary energy consumption compared to the same air conditioning system served by a conventional grid power and a boiler in the cooling season. Therefore, the LDIDECOAS achieved considerable energy savings when driven by the $\mathrm{ORC}$ and a district heat source in residential buildings. Additional studies are required to analyze the annual energy consumption.

\section{Acknowledgements}

This work was supported by the Korean Agency for Infrastructure Technology Advancement (KAIA) grants (19CTAP-C141826-02), and by the Korean Institute of Energy Technology Evaluation and Planning (KETEP) (No. 20184010201710).

\section{References}

Dong, H.W., Lee, S.J., Yoon, D.S., Park, J.Y., and Jeong, J.W. 2017. Impact of district heat source on primary energy savings of a desiccant-enhanced evaporative cooling system. Energy, Vol. 123, pp. 432-444.

Hasan, A. 2012. Going below the wet-bulb temperature by indirect evaporative cooling: Analysis using a modified $\varepsilon$-NTU method. Applied Energy, Vol. 89, pp. 237-245.

Kim, M.H., Park, J.Y., and Jeong, J.W. 2015. Simplified model for packed-bed tower regenerator in a liquid desiccant system. Applied Thermal Engineering, Vol. 89, pp. 717-736.

Kim, M.H., Dong, H.W., Park, J.Y., and Jeong, J.W. 2016. Primary energy savings in desiccant and evaporative cooling-assisted $100 \%$ outdoor air system combined with a fuel cell. Applied Energy, Vol. 180, pp. 446456.

Kozubal, E., Woods, J., Burch, J., Boranian, A., and Merrigan, T. 2011. Desiccant enhanced evaporative air-conditioning (DEVap): evaluation of a new concept in ultra efficient air conditioning. National Renewable Energy Laboratory.

Kozubal, E., Woods, J., and Judkoff, R. 2012. Development and analysis of desiccant enhanced evaporative air conditioner prototype. National Renewable Energy Laboratory.

Lee, S.J., Kim, H.J., Dong, H.W., and Jeong, J.W. 2016. Energy performance and applicability comparison of two different types of liquid desiccant assisted evaporative cooling systems. CLIMA 2016Proceedings of the 12th REHVA World Congress.

Liu, Z., Allen, W., and Modera, M. 2013. Simplified thermal modeling of indirect evaporative heat exchangers. HVAC\&R Research, Vol. 19, pp. 257267.

Martin, V. and Goswami, D.Y. 2000. Effectiveness of heat and mass transfer processes in a packed bed liquid desiccant dehumidifier/regenerator. $H V A C \& R$ Research, Vol. 6(1), pp. 21-39. 